\title{
Healthy Hunger-Free Kids Act Increases Phytochemicals in Menus and Curriculum Furthers Identification of Phytochemical-Rich Foods
}

\author{
D. Brewer ${ }^{1 *}$, S. Hershberger ${ }^{2}$ and L. Gaetke ${ }^{1}$ \\ ${ }^{1}$ University of Kentucky, Department of Dietetics and Human Nutrition, Lexington, USA \\ ${ }^{2}$ Miami University of Ohio, Department of Chemistry and Biochemistry, Oxford, USA
}

Received: January 27, 2016; Accepted: February 27, 2016; Published: March 09, 2016

*Corresponding author: Dawn Brewer, Assistant Professor, Department of Dietetics and Human Nutrition, University of Kentucky, 209C Funkhouser Building, Lexington, KY 40506, Tel: +859-257-1661; Fax: 859-257-3707; E-mail address: Dawn.Brewer@uky.edu

\begin{abstract}
Objective: This study evaluated whether providing the Fruits and Vegetables $(\mathrm{F} / \mathrm{V})$ required by the Healthy Hunger-Free Kids Act (HHFKA) increased phytochemical/antioxidant content of school lunches. Additionally, the ability of adolescents to apply their nutritional knowledge following participation in a nutrition-focused science-based curriculum was assessed.
\end{abstract}

Methods: Changes in antioxidant/phytochemical content from $\mathrm{F} / \mathrm{V}$ offered in school lunch menus were analyzed Pre-and Post-HHFKA. Food logs completed by 717 youth aged 10-18 were analyzed for correctly identifying "fighting foods".

Results: Significant increases in antioxidant/phytochemical content resulted following implementation of HHFKA $(P<0.05)$. Seventy-five percent $[0,100]$ of the time students accurately identified "fighting foods" in their one-day in-school food log $(n=468)$.

Conclusions and Implications: Creatively incorporating nutrition education into core curriculum, when paired with a supportive built environment that increases $\mathrm{F} / \mathrm{V}$ access (HHFKA), generates a multilevel intervention promoting $\mathrm{F} / \mathrm{V}$ consumption among school-aged youth.

Keywords: Phytochemicals, Environmental contaminants, Healthy Hunger-Free Kids Act, School lunch and/or National school lunch program

\section{Introduction}

Improving the school lunch environment with healthier foods has been an ongoing goal of the National School Lunch Program (NSLP) since 1946 [1]. But progress has been slow [2]. The most recent effort was the congressional passage of the 2010 Healthy, Hunger-Free Kids Act (HHFKA), which required the US Department of Agriculture (USDA) to update school meal patterns and nutrition standards [3]. The HHFKA required increases in amount and variety of fruits and vegetables (F/V) served in the NSLP beginning School Year (SY) 2012-2013. The new meal pattern called for age-dependent increases in the number of $\mathrm{F} / \mathrm{V}$ requiring $3 / 4$ to 1 cup of vegetables/day and $1 / 2$ to 1 cup of fruits/day, which differed from previous policies requiring $1 / 2$ to 1 cup of fruits or vegetables offered/day. Furthermore, the HHFKA established weekly age-dependent amounts of vegetablesubgroups to be served. By changing the built environment in this manner, the expectation was that NSLP participants would consume more F/V [4], and subsequently increase phytochemical and antioxidant vitamin intake. Phytochemicals are components found in plant matter including fruits, vegetables, legumes, and grains. Along with the nutrients found in plant foods, phytochemicals are believed to protect against chronic diseases through their anti-inflammatory and antioxidant properties [4]. Antioxidant vitamins include pre-form vitamin A, C, and E, and are best obtained from whole foods, especially F/V [3]. The first effort of the current study examined the changes in the estimated phytochemical and antioxidant vitamin content following implementation of the HHFKA.

Including an educational component in school classes to supplement changes in the built environment to support behavior change has been done previously [5]. The Fighting Foods: Battling Chemical Toxicity with Good Nutrition (Fighting Foods Project) is an example of a curriculum that teaches youth how $\mathrm{F} / \mathrm{V}$ can protect their health that happens to pair nicely with the built environment changes of the HHFKA policy, which provides students the opportunity to consume more F/V [4,6,7]. Scientific evidence increasingly suggests that poor diets (e.g., refined foods high in fat/calories, decreased intake of $F / V$ ) may increase the risk for oxidative stress, inflammation, and chronic diseases. Chronic exposure to environmental pollutants may also lower concentrations of antioxidants in the body and play a significant role in chronic disease development [8,9]. Researchers are finding that good nutrition and healthy food choices may reduce the negative effects of toxic exposure $[8,9]$.

The second effort of this study assessed student knowledge pertaining to foods that provided phytochemicals and antioxidant 
vitamins following delivery of the Fighting Foods pilot project, which was developed by middle and high school science educators and university researchers studying environmental pollutant exposure and nutrition. The Fighting Foods program offers 8 - 10 sets of classroom instructional materials into middle and high school chemistry, biology, general science and health classes designed to creatively bring the results of current biomedical research on nutrition and toxic exposure into the classroom; incorporate best Science, Technology, Engineering And Mathematical (STEM) education practices [10]; and lead to improved academic achievement and healthy food choices. The concurrent implementation of the HHFKA and the Fighting Foods Project provided a multi-level strategy that encouraged students to consume more F/V.

The objectives of this study were to:

1) Determine if the required increase in variety and quantity of F/V offered through the NSLP by the HHFKA significantly increased phytochemical and antioxidant content of school lunches and

2) Examine the ability of adolescents to apply their nutritional knowledge in food choices following participation in the Fighting Foods Project.

\section{Methods}

School lunch menus pre-HHFKA (SY2011-2012) and post (SY2012-2013) were obtained from a set of feeder schools including an elementary, middle and high school in the same district for a total of three schools. The estimated phytochemical and antioxidant content of the menus were analyzed using Nutrition Data System for Research software [11]. For each F/V listed/day of the four-week cycle menus pre and post-HHKFA, for each school. The vitamins and phytochemicals measured included flavonoids, carotenoids, and vitamins C and E. Due to the unavailability of an entire set of school lunch menus for SY2011-2012 the repetitive nature of the cycle menu was used to calculate differences in vitamin and phytochemical content between time periods. The nutrient content of the four-week cycle menu was repeated nine times for data analysis to mimic the 180 days of a SY. However, for certain menu items the ingredient information was not available thereby excluding these days from analysis (Dragon punch, veggies w/dip, and hummus) along with outliers. Since the variable "total phytochemicals and vitamins" consisted of all the phytochemicals and vitamins per day it was used to detect outliers for pre- and post-HHFKA.

The menu data of all schools was combined to create "all schools" variable. Due to "fresh fruit" varying throughout the SY, phytochemical and antioxidant content for a standard serving of each fruit was combined, averaged and used in the menu analysis each time a "fresh fruit" was offered. The combined "fresh fruit" variable for pre- and post- HHFKA included apples, oranges, bananas, kiwi, red grapes, peaches, and pears.

The Fighting Foods Project incorporated 8 - 10 sets of classroom instructional materials into middle and high school chemistry, biology, and general science classes [11]. The instructional material lessons included such topics as "The role of antioxidants in reducing PCB-induced inflammation" and "Is there a gene for liking broccoli". Activities utilized to reinforce concepts included magazine-style background readings; handson chemistry investigations that emphasized student-centered pedagogies; and classroom cooking and tasting experiences, each lesson reinforced which nutrients and associated foods were "fighting foods". Lessons defined so-called "fighting foods," as foods high in phytochemicals and antioxidant vitamins and included fruits, vegetables, $100 \% \mathrm{~F} / \mathrm{V}$ juices (fruit punch excluded), calcium-containing dairy products, and water. Students completed a one-day in-school food log that included foods consumed at school on one school day following completion of two Fighting Foods Project lessons taught over a two week period. Food logs included columns to list foods, serving sizes, food group, and if food was a fighting food (Y, N/or blank). Methods for collecting food logs and dietary recalls were taught by faculty and graduate students, who were also credentialed as registered dietitians from the University Of Kentucky's Superfund Research Center (UK-SRC) Community Engagement Core (CEC) to teachers participating in the summer training workshops. The training lasted approximately one hour and covered topics such as serving sizes and categorizing foods by food groups according to Choose My Plate guidelines.

A total of 717 youth 10-18 years from 9 middle and 8 high schools in Ohio returned the food logs during SY2014.

All procedures involving human subjects were approved by the University of Kentucky and the University of Miami at Ohio Institutional Review Boards. Written consent was obtained from teachers and assent from parents. Menu analysis did not require IRB approval because human subjects were not involved, as per US DHHS guidelines [12].

All data analyses were conducted using SAS (Version 9.3) [13]. The Shapiro-Wilk test revealed non-normal distribution of food log and menu data $(P \leq 0.05)$. Knowledge of fighting foods was assessed by calculating the percentage of correctly categorized fighting foods for each student by dividing the number of correctly categorized foods by the total number of foods consumed. The median was calculated for these frequencies of correctly identified fighting foods. The total of each continuous variable was calculated for each day by summing the phytochemical or vitamin variable for every fruit and vegetable listed/day. The median for each variable was calculated for both time periods to generate the median differences that were compared. $P \leq 0.05$ was statistically significant.

\section{Results}

Significant changes in vitamin and phytochemical content varied with school type post-HHFKA. The elementary school menu showed an increase in Anthocyanidins $(P \leq 0.002)$, Flavanols $(P \leq 0.001)$, and Carotenoids $(P \leq 0.001)$ post-HHFKA implementation (Table 1). The middle school menus revealed significantincreases in Vitamin $(P \leq 0.001)$ and the phytochemicals, Flavones $(P \leq 0.05)$, flavanols $(P \leq 0.001)$, and carotenoids $(P \leq 0.001)$; and a decrease inflavan-3-ols $(P<0.001)$. Finally, the 
Table 1: Median Difference in Phytochemical and Antioxidant Content of School Lunch Menus Pre- and Post-HHFKA.

\begin{tabular}{|c|c|c|c|c|c|c|c|c|c|}
\hline & \multicolumn{3}{|c|}{ Elementary School $(n=144)$} & \multicolumn{3}{|c|}{ Middle School (n=153) } & \multicolumn{3}{|c|}{ High School $(n=143)$} \\
\hline Phytochemical/Vitamin & $\begin{array}{c}\text { Pre- } \\
\text { Median }^{\mathrm{a}} \\
(\mathrm{IQR})^{\mathrm{b}}\end{array}$ & $\begin{array}{l}\text { Post- } \\
\text { Median } \\
\text { (IQR) }\end{array}$ & $\begin{array}{c}\text { Median } \\
\text { difference } \\
\text { (IQR ) }\end{array}$ & $\begin{array}{c}\text { Pre- } \\
\text { Median } \\
\text { (IQR) }\end{array}$ & $\begin{array}{c}\text { Post- } \\
\text { Median } \\
\text { (IQR) }\end{array}$ & $\begin{array}{c}\text { Median } \\
\text { difference } \\
\text { (IQR) }\end{array}$ & $\begin{array}{c}\text { Pre- } \\
\text { Median } \\
\text { (IQR) }\end{array}$ & $\begin{array}{c}\text { Post- } \\
\text { Median } \\
\text { (IQR) }\end{array}$ & $\begin{array}{l}\text { Median } \\
\text { difference } \\
\text { (IQR) }\end{array}$ \\
\hline Vitamin C(mg/serving) & $\begin{array}{c}28.3 \\
(24.4)\end{array}$ & $\begin{array}{c}26.9 \\
(34.5)\end{array}$ & $\begin{array}{c}-0.6 \\
(35.0)\end{array}$ & $\begin{array}{c}28.2 \\
(21.4)\end{array}$ & $\begin{array}{c}24.2 \\
(31.7)\end{array}$ & $\begin{array}{c}-0.4 \\
(33.9)\end{array}$ & $\begin{array}{c}45.1 \\
(26.7)\end{array}$ & $\begin{array}{c}75.8 \\
(39.8)\end{array}$ & $21.7 *(52.6)$ \\
\hline Vitamin E(IU/serving) & $\begin{array}{c}2.0 \\
(4.0)\end{array}$ & $\begin{array}{c}1.0 \\
(2.5)\end{array}$ & $\begin{array}{c}0.0 \\
(6.0)\end{array}$ & $\begin{array}{c}3.0 \\
(5.0)\end{array}$ & $\begin{array}{c}2.0 \\
(4.0)\end{array}$ & $\begin{array}{c}0.0^{*} \\
(5.0)\end{array}$ & $\begin{array}{c}6.0 \\
(5.0)\end{array}$ & $\begin{array}{c}8.0 \\
(3.0)\end{array}$ & $\begin{array}{c}3.3^{*} \\
(5.0)\end{array}$ \\
\hline Anthocyanidin(mg/g) & $\begin{array}{c}0 \\
(3.5)\end{array}$ & $\begin{array}{c}0 \\
(0.0)\end{array}$ & $\begin{array}{c}0.0^{*} \\
(0.1)\end{array}$ & $\begin{array}{c}0 \\
(7.9)\end{array}$ & $\begin{array}{c}0 \\
(7.9)\end{array}$ & $\begin{array}{c}0.0 \\
(0.1)\end{array}$ & $\begin{array}{c}0.1 \\
(9.9\end{array}$ & $\begin{array}{c}9.9 \\
(0.0)\end{array}$ & $\begin{array}{c}9.8^{*} \\
(9.9)\end{array}$ \\
\hline Flavan-3-ols(mg/g) & $\begin{array}{c}0 \\
(1.7)\end{array}$ & $\begin{array}{c}0.1 \\
(3.6)\end{array}$ & $\begin{array}{c}0.0 \\
(3.0)\end{array}$ & $\begin{array}{c}1.7 \\
(6.1)\end{array}$ & $\begin{array}{c}0 \\
(1.3)\end{array}$ & $\begin{array}{l}-1.5^{*} \\
(6.1)\end{array}$ & $\begin{array}{c}7.6 \\
(7.7)\end{array}$ & $\begin{array}{c}7.6 \\
(2.2)\end{array}$ & $\begin{array}{l}5.2^{*} \\
(7.6)\end{array}$ \\
\hline Flavanones(mg/g) & $\begin{array}{c}0 \\
(8.1)\end{array}$ & $\begin{array}{c}0 \\
(8.1)\end{array}$ & $\begin{array}{c}0.0 \\
(8.4)\end{array}$ & $\begin{array}{c}0 \\
(9.5)\end{array}$ & $\begin{array}{c}0 \\
(9.5)\end{array}$ & $\begin{array}{c}0.0 \\
(8.8)\end{array}$ & $\begin{array}{c}11.4 \\
(11.4)\end{array}$ & $\begin{array}{c}11.4 \\
(11.5)\end{array}$ & $11.4^{*}(11.4)$ \\
\hline Flavones(mg/g) & $\begin{array}{c}0.0 \\
(0.3)\end{array}$ & $\begin{array}{l}0.03 \\
(0.3)\end{array}$ & $\begin{array}{c}0.0 \\
(0.3)\end{array}$ & $\begin{array}{c}0.2 \\
(0.4)\end{array}$ & $\begin{array}{c}0.0 \\
(0.3)\end{array}$ & $\begin{array}{c}0.0^{*} \\
(0.5)\end{array}$ & $\begin{array}{c}0.4 \\
(0.5)\end{array}$ & $\begin{array}{c}0.4 \\
(0.4)\end{array}$ & $\begin{array}{c}0.1^{*} \\
(0.5)\end{array}$ \\
\hline Flavanols(mg/g) & $\begin{array}{c}2.7 \\
(2.5)\end{array}$ & $\begin{array}{c}2.9 \\
(3.3)\end{array}$ & $\begin{array}{l}1.3^{*} \\
(7.1)\end{array}$ & $\begin{array}{c}2.8 \\
(2.4)\end{array}$ & $\begin{array}{c}3.6 \\
(5.1)\end{array}$ & $\begin{array}{c}1.2^{*} \\
(5.1)\end{array}$ & $\begin{array}{c}3.8 \\
(4.4)\end{array}$ & $\begin{array}{c}6.2 \\
(4.7)\end{array}$ & $\begin{array}{l}2.0^{*} \\
(6.4)\end{array}$ \\
\hline Carotenoids(mg/serving) ${ }^{\mathrm{b}}$ & $\begin{array}{c}1.6 \\
(1.4)\end{array}$ & $\begin{array}{c}3.2 \\
(3.8)\end{array}$ & $\begin{array}{l}1.3^{*} \\
(5.1)\end{array}$ & $\begin{array}{c}1.7 \\
(2.8)\end{array}$ & $\begin{array}{c}5.3 \\
(4.0)\end{array}$ & $\begin{array}{l}2.3^{*} \\
(5.3)\end{array}$ & $\begin{array}{c}2.0 \\
(2.3)\end{array}$ & $\begin{array}{c}3.3 \\
(4.4)\end{array}$ & $\begin{array}{c}1.1^{*} \\
(4.9)\end{array}$ \\
\hline
\end{tabular}

${ }^{a}$ The median values were calculated for each vitamin and phytochemical for the pre-HHFKA, post-HHFKA, and the median difference of post-HHFKA - pre-HHFKA.

${ }^{\mathrm{b}} \mathrm{IQR}$ = interquartile range

*Indicates significant change in phytochemical or vitamin content from pre-HHFKA to post-HHFKA, (post-values - pre-values) within each respective school menu. Wilcoxon Sign Rank test used to determine significance, $P \leq 0.05$.

${ }^{\mathrm{b}} \mathrm{mg} /$ serving includes summed total of $\mathrm{mg}$ beta-carotene equivalents/serving of provitamin A carotenoids (beta-carotene, alpha-carotene, betacryptoxanthin) and $\mathrm{mg} /$ serving of lutein, zeaxanthin and lycopene.

high school menus demonstrated increases in vitamins $\mathrm{E}(P \leq$ 0.001), $C(P \leq 0.001)$ and the phytochemicals anthocyanidins $(P \leq 0.001)$, flavan-3-ols $(P \leq 0.001)$, flavanones $(P \leq 0.001)$, flavones $(P \leq 0.02)$, flavonols $(P \leq 0.001)$, and carotenoids $(P \leq 0.001)$. The "all schools" data demonstrated increases in all the antioxidant vitamins and phytochemicals except for flavones $(P \leq 0.05$, data not shown).

Of the 717 Fighting Foods Project food logs returned, only 468 were completed as instructed. Food logs were excluded if the fighting foods column was left completely blank. The data revealed that $75 \%[0,100]$ of the time students accurately identified foods as a fighting food from their food log.

\section{Discussion}

The current study demonstrated a significant increase in the amount of protective phytochemicals and antioxidant vitamins following implementation of the HHFKA. To our knowledge this is the first study to confirm significant increases in several phytochemicals in school lunch menus as a result of implementing the HHFKA policies.

In addition, incorporating nutrition lessons into middle and high school science-based curriculum was successful in educating students about protective foods, or fighting foods, that defend the body against environmental pollutants, obesity, and inflammation. In this study, $75 \%$ of the time students correctly applied their nutrition knowledge to identify fighting foods as recorded in their one-day in-school food log.

With the rise in childhood obesity and exposure to environmental contaminants, educating students about phytochemicals is an important component of nutrition education in order to encourage students to consume $\mathrm{F} / \mathrm{V}$ to protect their health [14]. If students consumed the F/V offered in a school lunch they would meet approximately one third of the Dietary Guidelines for vegetables and half for fruit [3]. The flavonoid intake in the US is estimated to be $20 \mathrm{mg} /$ day [7]. For the current study, almost $1 / 4$ of these flavonoids could be consumed per day if students consumed all of the fruits and vegetables offered per day through the NSLP.

An often overlooked benefit of the required HHFKA policies to increase the quantity of fruits and vegetables and variety of vegetable sub-categories offered in school lunches subsequently provides an increased amount and variety of phytochemicals and antioxidants. The phytochemical content varies greatly among fruits and vegetables and with this variety comes an assortment of health benefits. More than 5000 individual dietary phytochemicals have been identified in fruits, vegetables, whole grains, legumes and nuts with a large percentage of them still undiscovered [4]. The flavonoid and carotenoid categories of phytochemicals are focused on in this discussion because the content of these phytochemicals were assessed in the current study using the USDA phytochemical database [15]. 
Flavonoids are the largest group of phenolic compounds found in fruits, vegetables and other plant foods [4]. Over 4000 flavonoids are estimated to have been identified in the literature. Epidemiological studies have consistently shown that high intakes of flavonoids are inversely associated with decreased risk of several chronic conditions $[4,16]$.

They have been associated with reducing coronary heart disease and cancer by acting as an antioxidant and as a metal chelator. Some flavonoids have been reported to have antiinflammatory properties mainly related to their ability to inhibit the production of inflammatory mediators such as prostaglandins, leukotrienes and nitric oxide [7]. Flavonoids are found in many plant-based foods and beverages including apples, onions, tea, grapefruit, oranges, broccoli and kale, spinach, and lettuce. Furthermore, a number of these high flavonoid foods may appear in a school lunch menu [7].

Carotenoids are synthesized only in plants and more than 600 types of carotenoids have been identified [17]. But only approximately 40 are consumed in a typical human diet [7]. Carotenoids from fruits and vegetables have garnered much attention because of their health benefits and role in decreasing the risk of developing several chronic diseases [17]. Major sources of dietary carotenoids include orange and yellow fruits and vegetables such as tomatoes, carrots, sweet potatoes, and citrus fruits as well as green leafy vegetables [7] that are commonly served in school lunches. The average dietary intake of total carotenoids is estimated to be $6-11 \mathrm{mg} /$ day. Based on estimates from the menus used in this study, students could consume an average of approximately $5 \mathrm{mg}$ /day of total carotenoids by consuming all of the fruits and vegetables offered in their school lunch. Carotenoids are important components of the diet because they have been associated with health benefits including reduced coronary heart disease, age-related diseases of the eye, and cancer by functioning as an antioxidant [7].

Several studies have demonstrated that an attainable amount of whole fruits and vegetables consumed through diet as an addition to subjects' usual dietary pattern showed positive effects on serum markers of cellular oxidation and inflammation. The addition of fruits and vegetables to school lunches follows this same notion as there are no additional changes in usual diet. A study by Holt EM [6] found that consumption of approximately 2.75 cups of fruits and vegetables per day ( $\sim 15 \mathrm{mg}$ flavonoids) among adolescents aged 13-17 years was correlated with decreased markers of inflammation and oxidative stress. After controlling for sex, age, race, Tanner stage, energy intake and BMI, the pro-inflammatory markers C-Reactive Protein (CRP), Interleukin 6 (IL-6) and Tumor Necrosis Factor Alpha (TNF-A) were significantly decreased as was the marker of oxidative stress, F2-isoprostanes. These findings demonstrate that even at a young age fruit and vegetable consumption does have an impact on biomarkers of inflammation and oxidative stress, which is important because the pathophysiology of cardiovascular disease begins early in life, particularly among obese children $[18,19]$. The HHFKA essentially promoted an increase in the amount and variety of phytochemicals and antioxidants available in the school lunch menu. Consuming various fruits and vegetables early in life is an important strategy towards decreasing adverse health events in adulthood. With more than a third of children and adolescents considered overweight or obese [20], reducing chronic disease factors such as inflammation and oxidative stress is critically important. Another study conducted among youth demonstrated that consumption of dried apples enriched with mandarin juice by 48 obese adolescents, aged 9 to 15 years, for 4 weeks significantly increased antioxidant capacity as measured by the Ferric Reducing Antioxidant Power (FRAP) assay and significantly decreased the inflammatory markers CRP, IL-6, Interleukin-1 Alpha (IL-1 $\alpha$ ) and TNF-A [21]. The dried apples were added as a snack that contained approximately 7 mg of flavonoids in one snack bag. Subjects were instructed to consume one snack bag per day while following their usual dietary and physical activity patterns. Additionally, the study reported improvements in blood lipids with significant decreases in serum triglycerides, LDL cholesterol and an increase in HDL cholesterol.

A separate study by the same authors [22]. Found that supplementing the diet of 48 hyperlipidemic, normal weight youth, aged $8-12$ years, with 2 cups per day of $100 \%$ mandarin juice for 4 weeks significantly decreased markers of lipid and protein oxidation while increasing serum antioxidants glutathione and vitamins $\mathrm{E}$ and C. However, the juice supplementation did not affect blood lipids. The reported total polyphenol content of the juice was approximately $30 \mathrm{mg} / 500 \mathrm{ml}$ of juice. This study demonstrates that $100 \%$ fruit juice is also an important source of phytochemicals.

Through the school lunch program an adolescent would not consume two cups of juice, but a half cup of $100 \%$ fruit juice is considered a fruit serving that is likely to contain a unique composition of phytochemicals beneficial to health that is in a form readily consumed by youth [23].

The impact of the addition of fruits and vegetables for a period of time much shorter than the 180 days of a school year has demonstrated beneficial changes in biomarkers. A study conducted over a two-week period demonstrated that the daily addition of only two cups of a Mediterranean soup containing approximately $13.3 \mathrm{mg}$ carotenoids and $78 \mathrm{mg}$ vitamin C significantly decreased various markers of inflammation and oxidative stress [24]. Furthermore, a study by Riso et al. [25]. Found that ten day consumption of approximately 1.6 cups of cooked broccoli among smokers decreased CRP levels, which again demonstrates that small increases in fruit and vegetable intake can positively impact biomarkers in a short amount of time.

Implementation of the HHFKA makes small, but potentially impactful increases in fruits and vegetables available to youth on a regular basis. An obvious barrier to obtaining these health benefits is the lack of consumption of fruits and vegetables by students [26]. The limited amount of available evidence pertaining to fruit and vegetable consumption following the strengthening of meal standards by HHFKA are contradictory, demonstrating low intake of vegetables [26]. As well as increased 
fruit consumption without an increase in plate waste [27]. Some studies have demonstrated that gaining nutrition knowledge is more effective when initiated at a younger age [3] and combined with an environment promoting student health [28]. School teachers are an important component of the school environment as they are critical to encouraging $\mathrm{F} / \mathrm{V}$ consumption among youth because they reach a large audience in a meaningful way that provides continuous and intensive contact [29], however they also face constraints of adding such content as nutrition to their core curriculum. The Fighting Food Project integrated nutrition and health topics into curriculum without detracting from the core science curriculum. By pairing science experiments, including the chemistry of foods and environmental chemicals, such as lead, students had an opportunity to learn how nutrition can reduce the risk of environmental exposures and disease. Combining nutrition knowledge with a built environment that supports increased access to $\mathrm{F} / \mathrm{V}$ provides a multi-level intervention that encourages students to consume F/V during school lunch.

The present study has limitations. Each day of the school lunch menu could not be assessed individually. Obtaining a complete set of school lunch menus for an entire school year prior to HHFKA remains a challenge. However, due to the menus being planned using a four-week cycle, the results would have been similar. The actual phytochemical content of the school lunch menu was not assessed because there is no available dataset containing all phytochemicals found in all plant matter. The USDA phytochemical database [15], however, is a valuable resource to assess changes in flavonoid content and provided the most accurate information available. Additionally, increases in specific phytochemicals and vitamins would likely vary among schools and menus due to differences in menus before and after implementation of the HHFKA. Schools across the US that were already in compliance with the HHFKA requirements would not have shown an increase in phytochemical content because their menus already contained a higher concentration of phytochemicals compared to schools following previous standards. For example the menus in this study were in compliance with whole wheat requirements preHHFKA therefore, grain products were not included in analysis. Also, the pre-HHFKA elementary and middle school menus used in this study was likely closer to compliance with the policies of the HHFKA than the high school lunch menus. The high school lunch menu showed the most increases in vitamin and phytochemical content from pre- to post-HHFKA compared to the elementary and middle school menus. This was likely a result of the post-HHFKA high school menu needing to incorporate more F/V to meet the age-dependent increases of the new meal patterns required by the HHFKA.

As to the Fighting Foods Project, the food logs were not part of the original evaluation components of the science curriculum and did not include testing for validity and reliability of school-level measures. Students' responses were self-reported and subject to recall and common response bias. Future studies may include more sophisticated dietary recall measures that more accurately capture dietary intake and plate waste.

\section{Disclaimer}

The content is solely the responsibility of the authors and does not necessarily represent the official views of the National Center for Research Resources or the National Institutes of Health.

\section{Source of support}

Funding for this project was provided by National Center for Research Resources (Award\# R25RR032208).

\section{Acknowledgements}

Funding for this project was provided by National Center for Research Resources (Award\# R25RR032208). The authors would also like to thank Siddhi Shroff and Evansville Vanderburgh School Corporation.

\section{References}

1. Gunderson G. National School Lunch Program (NSLP) Background and Development. 2014.

2. Turner L, Chaloupka FJ. Slow progress in changing the school food environment: nationally representative results from public and private elementary schools. J Acad Nutr Diet. 2012; 112(9): 1380-9. Doi: 10.1016/j.jand.2012.04.017.

3. United States Department of Agriculture Food and Nutrition Service. National School Lunch Program and School Breakfast Program: nutrition standards for all foods sold in school as required by the Healthy, Hunger-Free Kids Act of 2010. Interim final rule. Federal register. 2013; 78: 39067-120.

4. Liu RH. Health-promoting components of fruits and vegetables in the diet. Adv Nutr. 2013; 4(3): 384S-92S. Doi: 10.3945/an.112.003517.

5. Wang D, Stewart D. The implementation and effectiveness of schoolbased nutrition promotion programmes using a health-promoting schools approach: a systematic review. Public Health Nutr. 2013; 16(6): 1082-100. Doi: 10.1017/S1368980012003497.

6. Holt EM, Steffen LM, Moran A, Basu S, Steinberger J, Ross JA, et al. Fruit and vegetable consumption and its relation to markers of inflammation and oxidative stress in adolescents. J Am Diet Assoc. 2009; 109(3): 414-21. Doi: 10.1016/j.jada.2008.11.036.

7. Kryzanowska J, Czubacka A, Oleszek W. Dietary Phytochemicals and Human Health. In: Giardi MT, Rea G, Berra B, editors. Bio-Farms for Nutraceuticals: Functional Food and Safety Control by Biosensors New York, New York: Landes Biosciences; 2010. p. 74.

8. Hennig B, Reiterer G, Majkova Z, Oesterling E, Meerarni P, Robertson LW. Nutrition Modulates PCB Toxicity: Implications in Atherosclerosis. Urbana and Chicago: University of Illinois Press; 2008.

9. Petriello MC, Newsome BJ, Dziubla TD, Hilt JZ, Bhattacharyya D, Hennig $\mathrm{B}$, et al. Modulation of persistent organic pollutant toxicity through nutritional intervention: emerging opportunities in biomedicine and environmental remediation. Sci Total Environ. 2014; 491-492: 11-6. Doi: 10.1016/j.scitotenv.2014.01.109.

10. National Research Council. A Framework for K-12 Science Education: Practices, Crosscutting Concepts and Core Ideas. In: Standards CoaCFfNK-SE, editor. Washington, DC: Board on Science Education, Division of Behavioral and Social Sciences and Education; 2012.

11. Nutrition Coordinating Center. Nutrition Data System for Research Minneapolis, MN: University of Minnesota; 2014. 
12.U.S. Department of Health \& Human Services. Human Subject Regulations Decision Charts. Chart 1: Is an Activity Research Involving Human Subjects? 2004.

13. Statistical Analysis System (SAS) Institute. The SAS system for Windows. Release 9.3. Cary, North Caroline: SAS Institute; 2012.

14. Worsley A. Nutrition knowledge and food consumption: can nutrition knowledge change food behavior? Asia Pacific journal of clinical nutrition. 2002; 11 Suppl 3: S579-85

15. Bhagwat S, Haytowitz DB, Holden JM. USDA Database for the Flavonoid Content of Selected Foods, Release 3.1.: U.S. Department of Agriculture; 2013.

16. Liu RH. Potential synergy of phytochemicals in cancer prevention: mechanism of action. J Nutr. 2004; 134(12 Suppl): 3479S-3485S.

17. Khoo HE, Prasad KN, Kong KW, Jiang Y, Ismail A. Carotenoids and their isomers: color pigments in fruits and vegetables. Molecules. 2011; 16(2): 1710-38. Doi: 10.3390/molecules16021710.

18. Kones R, Rumana U. Cardiovascular prevention: components, levels, early origins, and metrics. Hosp Pract (1995). 2014; 42(3): 84-95. Doi: 10.3810/hp.2014.08.1121

19. D’Adamo E, Guardamagna O, Chiarelli F, Bartuli A, Liccardo D, Ferrari F,et al. Atherogenic dyslipidemia and cardiovascular risk factors in obese children. Int J Endocrinol. 2015; 2015: 912047. Doi: $10.1155 / 2015 / 912047$.

20. Ogden CL, Carroll MD, Kit BK, Flegal KM. Prevalence of childhood and adult obesity in the United States, 2011-2012. JAMA. 2014; 311(8) 806-14. Doi: 10.1001/jama.2014.732.

21. Codoñer-Franch P, Betoret E, Betoret N, López-Jaén AB, VallsBellés V, Fito $\mathrm{P}$, et al. Dried apples enriched with mandarin juice by vacuum impregnation improve antioxidant capacity and decrease inflammation in obese children. Nutr Hosp. 2013; 28(4): 1177-83. Doi: 10.3305/nh.2013.28.4.6580

22. Codoñer-Franch $P$, López-Jaén $A B$, Muñiz $P$, Sentandreu $E$
Bellés VV. Mandarin juice improves the antioxidant status of hypercholesterolemic children. J Pediatr Gastroenterol Nutr.2008; 47(3): 349-55. Doi: 10.1097/MPG.0b013e31816a8cdb.

23. O'Neil CE, Nicklas TA, Zanovec M, Fulgoni VL 3rd. Diet quality is positively associated with $100 \%$ fruit juice consumption in children and adults in the United States: NHANES 2003-2006. Nutr J. 2011; 10 : 17. Doi: 10.1186/1475-2891-10-17.

24. Sánchez-Moreno C, Cano MP, de Ancos B, Plaza L, Olmedilla B, Granado $\mathrm{F}$, et al. Mediterranean vegetable soup consumption increases plasma vitamin C and decreases F2-isoprostanes, prostaglandin E2 and monocyte chemotactic protein-1 in healthy humans. J Nutr Biochem. 2006; 17(3): 183-9.

25. Riso P, Vendrame S, Del Bo' C, Martini D, Martinetti A, Seregni E, et al. Effect of 10-day broccoli consumption on inflammatory status of young healthy smokers. Int J Food Sci Nutr. 2014; 65(1): 106-11. Doi: 10.3109/09637486.2013.830084.

26. Smith SL, Cunningham-Sabo L. Food choice, plate waste and nutrient intake of elementary- and middle-school students participating in the US National School Lunch Program. Public Health Nutr. 2014; 17(6): 1255-63. Doi: 10.1017/S1368980013001894.

27. Schwartz MB, Henderson KE, Read M, Danna N, Ickovics JR. New school meal regulations increase fruit consumption and do not increase total plate waste. Child Obes. 2015; 11(3): 242-7. Doi: 10.1089/ chi.2015.0019.

28. Sichert-Hellert W, Beghin L, De Henauw S, Grammatikaki E, Hallström L, Manios Y, et al. Nutritional knowledge in European adolescents: results from the HELENA (Healthy Lifestyle in Europe by Nutrition in Adolescence) study. Public Health Nutr. 2011; 14(12): 2083-91. Doi: 10.1017/S1368980011001352.

29. Ernst JA, Snelling A, Ellsworth D. Integrating Concepts about Food, Nutrition and Physical Activity into Middle School Curriculum. Community Voices for Health Teachers Take Action: American University; 2013. 